\title{
Spontaneous Bacterial Peritonitis and Bacteremia in Patients with Liver Cirrhosis
}

Toru Shizuma*

Department of Physiology, School of Medicine, Tokai University, Japan

*Corresponding author: Toru Shizuma, Department of Physiology, School of Medicine, Tokai University, 143, Shimokasuya, Isehara, Kanagawa, 259-1193, Japan; Tel : +81-0463-93-1121; Fax : +81-0463-93-6684; E-mail : shizuma@is.icc.u-tokai.ac.jp

Rec Date: Jan 04, 2014, Acc date: June 27, 2014, Pub date: June 30, 2014

Copyright: $\odot 2014$ Shizuma T. This is an open-access article distributed under the terms of the Creative Commons Attribution License, which permits unrestricted use, distribution, and reproduction in any medium, provided the original author and source are credited

\begin{abstract}
Patients with Liver Cirrhosis (LC) are at high risk of developing bacterial infections. Pathological bacterial translocation has been implicated as an important cause of bacterial infection in patients with LC, and Spontaneous Bacterial Peritonitis (SBP) and bacteremia are common and often fatal bacterial infections in these patients. Moreover, the incidence of hepatorenal syndrome is associated with bacterial infections such as SBP; in addition, the syndrome is often fatal in patients with LC. The frequency of isolation of multidrug-resistant (MDR) organisms in patients with LC and bacterial infections has been reported to be increasing in recent years, and infections caused by MDR organisms appear to be associated with poor prognoses. However, further research is required to better understand bacterial infections in the setting of LC because there remain unresolved problems related to this issue. This review summarizes the frequency, diagnoses, causative organisms, prognoses, and treatment of SBP and bacteremia in patients with LC.
\end{abstract}

Keywords Bacteremia; Spontaneous bacterial peritonitis; Hepatorenal syndrome; Bacterial infection; Liver cirrhosis

\section{Introduction}

Patients with Liver Cirrhosis (LC) are at high risk of developing bacterial infections because of the hypoactivity of phagocytic cells in the hepatic reticuloendothelial system as well as bacterial influx into the general circulation through portacaval shunts [1-8]. It is reported that $30 \%-60 \%$ in patients with LC develop a bacterial infection [1-6,8-10], and bacterial infections are involved in approximately $25 \%$ deaths among patients with LC $[6,11,12]$. Moreover, the incidence of bacterial infection in patients with LC is $4-5$-fold higher than that in the generation population [13].

In patients with $\mathrm{LC}$, the most common bacterial infections are Spontaneous Bacterial Peritonitis (SBP), urinary tract infection, pneumonia (respiratory infection), soft tissue infection, and bacteremia [4-6,8-10,14-16]. A delay in the diagnosis of a bacterial infection often leads to fatal outcomes in patients with LC [17]. Once bacterial infection occurs, the increased production of proinflammatory cytokines such as tumor necrosis factor- $\alpha$ and interleukin-6 coupled with hemodynamic derangement results in serious consequences that may include sepsis or multiple organ failure $[5,6,9]$. The prognosis of severe sepsis and septic shock in patients with LC is extremely poor, and the hospital mortality rate of inpatients with LC has been reported to range from $30 \%$ to $70 \%$ [9].

In bacterial infections such as SBP, renal impairment is one of the prognostic factors, and type-1 hepatorenal syndrome (HRS) is associated with a particularly poor prognosis [18-26]. On the contrary, the prevalence of infections caused by multidrug-resistant (MDR) bacteria has increased in patients with LC in recent years, possibly because of the increasing frequency of antibiotic treatment [27-29].
The present paper reviews previous studies of patients with LC complicated by SBP, HRS, and bacteremia, which are frequently fatal in this population.

\section{Methods}

We conducted a literature search of studies published in the English language since 1981 using the PubMed (http://www.ncbi.nlm.nih.gov/ pubmed) database. We searched the literature using the following keywords:

(1) Spontaneous bacterial peritonitis and liver cirrhosis,

(2) Bacteremia and liver cirrhosis,

(3) Bacterial infection(s) and liver cirrhosis, and

(4) Hepatorenal syndrome and liver cirrhosis.

\section{Possible mechanisms underlying bacterial infections in patients with $\mathrm{LC}$}

Changes in the composition of the intestinal bacterial flora as well as the breakdown of the intestinal mucosa barrier because of gastrointestinal bleeding and pathological Bacterial Translocation (BT), which develops with a sustained increase in the rate and/or degree of BT [30], from the intestine to the mesenteric lymph node may be involved in the onset of SBP and bacteremia in patients with LC [6-8,30-33]. Pathological BT is reportedly common among patients with severe liver dysfunction [32,34], although BT itself has been estimated to be a healthy phenomenon [30,33]. Moreover, the possibility of genetic diversity and virulence of causative bacteria may influence the incidence of pathological BT as well as the severity of liver dysfunction [30,35]. Bert et al. [35] reported that some isolates of Escherichia coli, (E. coli) which is the most common Gram-negative bacterium involved in SBP in patients with LC, exhibit extensive virulence and that it may easily induce BT. It has been suggested that bacteremia develops more frequently among patients who have 
undergone catheterization or endoscopic procedures and those who experience gastrointestinal bleeding $[10,12]$.

The long-term use of Proton Pump Inhibitors (PPIs) may reportedly increase the risk of SBP because of the facilitation of intestinal BT, although this association is controversial [7,28,36-39]. Recently, Miura et al. [38] reported that the use of PPIs in patients with LC is an independent risk factor for the development of SBP [odds ratio (OR), 6.41; 95\% Confidence Interval (CI), 1.16-35.7; $\mathrm{p}=$ 0.033 ) using multivariate analysis. Kwon et al. [39] also reported that the use of PPIs was associated with the development of SBP and a high mortality rate associated with the same (adjusted OR, 1.960; 95\% CI, $1.190-3.227 ; \mathrm{p}=0.008)$.

\section{SBP in patients with $\mathrm{LC}$}

\section{Diagnosis of SBP}

SBP is defined as a bacterial infection of the ascitic fluid without any apparent intra-abdominal source of infection or malignancy [9]. Therefore, infectious pleural effusion, peritonitis carcinomatosa, and hemorrhagic ascites such as hepatocellular carcinoma rupture are excluded from the diagnosis of SBP. SBP is diagnosed in patients with a polymorphonuclear cell count of $\geq 250$ cells $/ \mathrm{mm} 3$ in the ascitic fluid, regardless of the isolation of bacteria from the fluid $[7,8,14,40]$.

Ascitic fluid culture is positive in $35 \%-65 \%$ patients with SBPs [8]. However, classical culture techniques fail to grow bacteria in up to $65 \%$ samples of neutrocytic ascites [7]. The positivity of culture in the ascitic fluid has been reported to increase by placement of the fluid directly into blood culture flasks at the bedside soon after collection $[7,8]$. The usefulness of measuring ascitic $\mathrm{pH}$ as well as lactate and lactoferrin levels in ascitic fluid for the diagnosis of SBP has not been confirmed [8].

\section{Frequency of SBP in patients with LC}

The incidence of SBP in inpatients with LC and ascites has been reported to be $7 \%-30 \%[7,41-45]$ compared with $1.5 \%-3.5 \%$ [43] in outpatients with LC.

\section{Causative organisms of SBP in patients with LC}

Pathological BT from the intestinal tract is considered as one of the mechanisms involved in SBP and bacteremia in patients with LC, and enterobacteria account for a relatively large percentage of the causative bacteria [46-48]. The single most frequently detected organism in ascitic fluid from patients with LC and SBP is E. coli [21,29,40,43-45,49]. Moreover, the most common Gram-negative bacteria involved in SBP in patients with LC are E. coli and Klebsiella spp., while the most common Gram-positive bacteria are Streptococcus spp., Staphylococcus spp., and Enterococci [40,43-45,49].

Moreover, nosocomial SBP infections are frequently caused by bacteria that are resistant to $\beta$-lactam antibiotics [9]. Recent reports indicated that a quarter of organisms isolated from patients with nosocomial SBP infections are resistant to multiple commonly used antibiotics [50]. In nosocomial infections in patients with LC and SBP, the frequency of isolation of MDR bacteria is high compared with that in patients with community-acquired infections [45].

\section{Predictive prognostic factors in patients with LC and SBP}

Factors predictive of the incidence of SBP among patients with LC and ascites include age; a low protein concentration $(<1.5 \mathrm{~g} / \mathrm{dL})$ in the ascitic fluid, which is estimated to be related to decreased opsonic activity in the ascitic fluid [7,28,43,49]; gastrointestinal bleeding [14,51]; and the severity of liver dysfunction [1,14,18,19,43,49,51]. Moreover, independent predictors of mortality in patients with LC and SBP include renal impairment, a nosocomial source of infection, severe sepsis, hemodynamic instability, and the severity of liver dysfunction [1,18-20,51].

Renal impairment, including HRS, is a major prognostic factor in patients with LC and SBP, and it is perhaps the most crucial factor associated with mortality [18-21,44]. Multivariate analysis by Tsung et al. [49] using a Cox proportional hazards model indicated that renal failure [serum creatinine $(\mathrm{Cr})$ level $>1.3 \mathrm{mg} / \mathrm{dL}$ ] is an independent predictor of hospital mortality in patients with LC and SBP (OR, 3.752; 95\% CI, 1.884-7.475; $\mathrm{p}<0.001)$ in addition to the presence of hepatocellular carcinoma at the time of SBP diagnosis, severe liver dysfunction, and low glucose levels in ascitic fluid. Multivariate analysis by Cheong et al. [52] using a Cox proportional hazards model indicated that acute renal failure [hazard ratio (HR), 3.14; 95\% CI, 2.11-4.68, p < 0.001), nosocomial infection (HR, 2.18; 95\% CI, 1.473.23; $\mathrm{p}<0.001$ ), and septic shock (HR, 1.71; 95\% CI, 1.11-2.62, $\mathrm{p}=$ 0.014 ) are independent predictors of 30-day mortality in patients with LC and SBP. Moreover, multivariate analysis by Terg et al. [21] using logistic regression indicated that renal failure is the only independent predictor of hospital mortality (OR, 15.9; 95\% CI, 3.8-49.3; $\mathrm{p}=0.002$ ) in these patients.

\section{HRS-associated SBP in patients with LC}

HRS occurs almost exclusively in patients with LC and ascites. Renal impairment such as HRS in patients with SBP is associated with a decreased circulating volume [53]. Patients with serum Cr levels $\geq$ $1.5 \mathrm{mg} / \mathrm{dL}$ and no evident disease associated with renal failure were diagnosed with HRS according to the criteria of the International Ascites Club [54]. These patients were then classified into two types: type 1, where the Cr level was increased two-fold or had reached 2.5 $\mathrm{mg} / \mathrm{dL}$ within 2 weeks, with rapid progression of renal failure, and type 2 , where the Cr level was $\geq 1.5 \mathrm{mg} / \mathrm{dL}$ with no rapid deterioration of renal function. According to Sort et al. [24], the incidence of type 1 HRS among patients with LC and SBP is approximately $30 \%$. Moreover, in 2007, new diagnostic criteria for HRS were established according to the International Ascites Club [55].

The probable occurrence of HRS in patients with LC and ascites for more than 5 years is as high as $40 \%$ [56]. One of the main precipitating conditions is bacterial infections such as SBP [56,57]. Patients with LC complicated by type $1 \mathrm{HRS}$ are considered to have a poor prognosis [21-23,25,57,58], and the 3 -month survival is $20 \%$ for type 1 HRS and $40 \%$ for type 2 HRS [57]. The median survival duration in patients with LC is reported to range from 2 weeks to 1 month for type 1 HRS and 4 to 7 months with type 2 HRS $[22,23,56,58]$, although the treatment of SBP with albumin infusion and antimicrobial agents reportedly decreases the risk of HRS development and improves survival $[24,40]$.

Although bacterial infections such as SBP are a frequent trigger of HRS [59], there is a scarcity of data on the natural history and outcome of type $1 \mathrm{HRS}$-associated bacterial infections in patients with LC [60]. Recently, a cohort study by Barreto et al. [60] illustrated that 
$67 \%$ (47/70) patients with LC and type 1 HRS associated with bacterial infections had no reversibility of HRS. They indicated that age, high baseline bilirubin levels, and nosocomial infection were independent predictors of the irreversibility of type-1 HRS using a multivariate model [60]. Moreover, they suggested that high baseline bilirubin levels, a lack of resolution of infections, and irreversibility of HRS were independent predictors of mortality in patients with LC and type 1 HRS associated with bacterial infections [60].

A meta-analysis of controlled studies found that terlipressin reverses HRS and improves renal impairment in nearly 50\% patients with LC [58]. The combination of vasoconstrictive agents and albumin has been suggested to be the most effective pharmacotherapy [26]. Some studies indicated that the prolonged use of ornipressin, terlipressin, or $\alpha$-agonist vasoconstrictors (e.g., midodrine plus octreotide, noradrenaline alone) in association with albumin is capable of recovering renal function in $40 \%-60 \%$ patients with type 1 HRS $[56,57]$. However, vasoconstrictor treatment with or without albumin does not improve the long-term prognosis [26,58]. Liver transplantation is the only rational treatment for type $1 \mathrm{HRS}$ as well as other complications [26].

\section{Indications for antibiotic prophylaxis in patients with LC and SBP}

Empirical antibiotic treatment must be initiated immediately after the diagnosis of SBP [40]. However, if the neutrophil count of the ascitic fluid decreases to $<25 \%$ of the pretreatment value after 2 days of antibiotic treatment for SBP, there is often an increased probability of failure to respond to any treatment $[40,45]$. It has been suggested that the combined use of antibiotics and albumin injections may prevent the aggravation of renal impairment such as HRS in patients with LC and SBP [9]. However, in patients with LC without bacterial infections, the use of prophylactic antibiotics must be restricted to patients who are at high risk of SBP because of an increasing risk of infection with MDR organisms [26,28].

\section{Primary prophylaxis in patients with LC and no prior history of SBP}

Patients with LC and a low protein concentration $(<1.5 \mathrm{~g} / \mathrm{dL})$ in ascitic fluid and/or high serum bilirubin levels are at risk of developing a first episode of SBP [28], and primary prophylaxis in patients with LC and no prior history of SBP is recommended when a low protein concentration in ascitic fluid and other factors (e.g., severe liver failure, impaired renal function, hyponatremia) are present $[9,26,28]$. Primary prophylaxis is also routinely indicated in patients with LC and acute gastrointestinal bleeding [26]. Wiest et al. [7] presented the utility of primary prophylaxis to prevent SBP by administering quinolones in three meta-analyses (Figure 1).

\section{Secondary prophylaxis in patients with LC who experienced a previous episode of SBP}

In patients with LC who recovered from a previous episode of SBP, the recurrence rate is as high as $70 \%$ in the absence of antibiotic prophylaxis [26]. Therefore, secondary prophylaxis is indicated for patients with a previous episode of SBP $[9,40]$. Secondary prophylaxis with norfloxacin decreased the recurrence rate from $68 \%$ to $20 \%$ $[26,28]$. Other randomized trials revealed a significant decrease in the recurrence of SBP with antibiotic prophylaxis including ciprofloxacin or trimethoprim/sulfamethoxazole $[26,28]$. However, the optimal duration of prophylaxis is unclear at present [28], although secondary prophylaxis should be indefinitely continued until the ascites is resolved or liver transplantation can be performed [26].

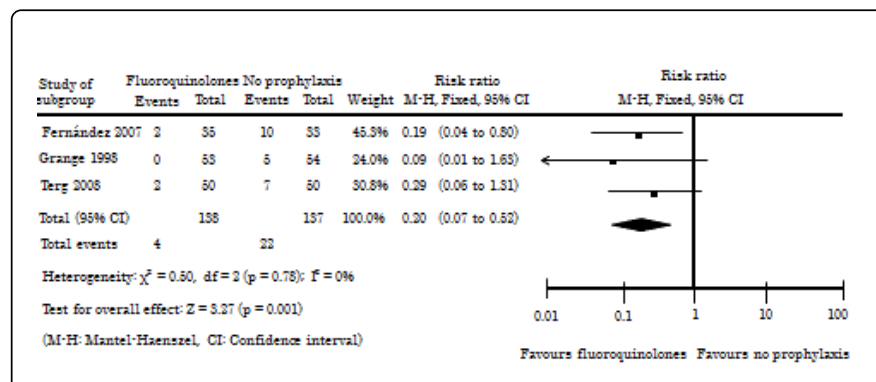

Figure 1: Meta-analysis: prevention of SBP in pure primary prophylactic randomized controlled trials.

\section{Prognosis of SBP}

When SBP was first described, the mortality rate associated with this condition exceeded $90 \%[40,43,49]$, although this has decreased as a result of early diagnoses and prompt treatment [14,43]. The recent hospital mortality rates of all cases of SBP were reported to be $10 \%-$ $50 \%$ for the first episode and $31 \%-93 \%$ for the second or subsequent episodes [7,61]. The mortality rates at 1 and 2 years following an episode of SBP are reported to be $50 \%-70 \%$ and $70 \%-75 \%$, respectively $[9,14]$.

Well-recognized predictors of mortality from SBP include age, severe liver disease, nosocomial origin (compared with communityacquired SBP), the presence of gene variants of causative organisms, and renal impairment $[7,52,62,63]$. A meta-analysis of published data (2002-2011) identified a four-fold increased risk of mortality associated with MDR bacteria in patients with LC and SBP [7]. Some reports indicated that the mortality rate of SBP associated with culture-positive ascitic fluid is higher than that associated with culture-negative neutrocytic ascites using multiple logistic regression analysis, although other reports found no significant difference in mortality rates between these groups [44].

\section{Bacteremia in patients with LC}

\section{Frequency of bacteremia in patients with LC}

The reported rate of bacteremia among inpatients with $\mathrm{LC}$ ranges from $3.5 \%$ to $8.8 \%$ in the literature $[1,2,64,65]$. This rate is reportedly four- to 11-fold higher than that for the general population of inpatients [64,66,67]. Kang et al. [17] reported that LC was significantly associated with an increased risk of mortality in patients with bacteremia compared with that that in patients with other underlying diseases using multivariate analysis

\section{Frequency of nosocomial infections in patients with LC and bacteremia}

The reported percentage of nosocomial infections among patients with LC and bacteremia varies widely from $24 \%$ to $70 \%[17,64,67,68]$. The actual value is likely to be affected by factors such as catheterization, extent of gastrointestinal tract treatment after hospital 
admission, and the use of antimicrobial agents. Thulstrup et al. [65] reported that nosocomial infection was associated with a higher risk of 30-day mortality (adjusted OR, 1.7; 95\% CI, 0.7-3.5) compared with community-acquired infection using logistic regression analysis.

\section{Causative organisms detected in patients with LC and bacteremia}

Gram-positive bacteria are responsible for bacteremia in 24\%-69\% patients with LC $[64,66]$. However, the rate of Gram-positive bacterial infection is also influenced by several factors, including catheterization, the use of cephem antibiotics, and the presence of softtissue infections.

Pathological BT is known to be strongly correlated with the presence of aerobic Gram-negative bacteria, including enterobacteria such as E. coli and Klebsiella spp., and these remain the most important causes of bacteremia in patients with LC [17,64,65,67-69]. On the contrary, Staphylococcus spp. are the most common Grampositive bacteria found in patients with LC and bacteremia $[17,64,65,67,68,70]$. Several studies reported no significant differences in either the severity of liver dysfunction or short-term prognosis between patients with bacteremia induced by Gram-positive bacteria and those infected with Gram-negative bacteria [64-66].

\section{Predictors of susceptibility and prognosis in patients with LC and bacteremia}

Susceptibility to bacteremia $[2,15,28,64,67,71,72]$ and the subsequent short-term prognosis $[64,69,70,72,73]$ in patients with LC are correlated with the severity of LC, which is an independent risk factor for mortality in patients with LC and bacteremia [17]. Moreover, the possibility of the development of renal impairment is significantly higher among patients with bacteremia than among those with negative blood culture [68]. Acute renal impairment after bacterial infections has often been observed [5,74], and it is also a strong independent risk factor for mortality in patients with LC $[5,75,76]$. In particular, type $1 \mathrm{HRS}$ is linked to an extremely poor prognosis and is associated with short-term mortality in patients with LC and bacteremia, as observed in patients with SBP. Therefore, both the severity of liver dysfunction and the presence of renal impairment are important prognostic factors in patients with LC and bacteremia [5,77]. Bouslama et al. [77] reported that the prevalence of renal dysfunction in patients with bacterial infections other than SBP and LC and a model for end-stage liver disease score of $>20$ was 7.39 -fold higher than that in other patients using multiple logistic regression analysis (OR, 7.39; 95\% CI, 2.13-25.612; $\mathrm{p}=0.002$ ). Several reports noted that the susceptibility to bacteremia does not appear to vary according to the etiology of LC, including hepatitis $\mathrm{B}$ or $\mathrm{C}$ infection or alcohol abuse $[64,67,71]$.

\section{Prognosis of bacteremia in patients with LC}

The mortality rate for patients with LC and complications developing from bacterial infection is markedly higher than that for uninfected patients $[11,64,69,72,73,75,78]$. Previous studies reported short-term mortality rates of $27 \%-60 \%$ in patients with LC complicated by bacteremia, although slightly different definitions of short-term mortality have been employed [5,17,65,66,75]. Furthermore, a cohort study suggested that LC with bacteremia is associated with a significantly increased risk of mortality compared with other conditions that may be complicated by bacteremia using multivariate logistic analysis [17].

\section{MDR bacteria-associated infections in patients with LC}

MDR bacteria are resistant to at least three of the primary antibiotic families, including $\beta$ - lactamase $[27,28]$. The main MDR bacteria are extended-spectrum $\quad \beta$-lactamase $\quad$ (ESBL)-producing Enterobacteriaceae, nonfermentable Gram-negative bacilli such as Pseudomonas aeruginosa, Acinetobacter baumannii, methicillinresistant Staphylococcus aureus (MRSA), and vancomycin-susceptible (VSE) or vancomycin-resistant Enterococci [13]. Moreover, MDR bacteria are increasingly frequent causative organisms of hospital- or health care-associated infections [28]. The proportions of MDR bacteria in patients with LC in recent studies from different geographic areas (2006-2012) were as follows: ESBL-producing Enterobacteriaceae, 4\%-29\%; Pseudomonas aeruginosa, 1\%-3\%; MRSA, $3 \%-8 \%$; and VSE, $1 \%-10 \%$. Moreover, the prevalence of ESBL-producing Enterobacteriaceae in patients with LC and SBP in recent multiple studies from Asia and Europe (2002-2009) has been reported to be $1.5 \%-18 \%$ [9]. Fernández et al. [27] investigated 669 bacterial infections in patients with LC in two series (2005-2007 and 2011-2012) and reported that infections caused by MDR bacteria are more common among nosocomial infections and carry a poorer prognosis (higher hospital mortality) compared with those caused by susceptible bacteria. Moreover, some authors reported that infections caused by MDR bacteria are associated with a higher mortality compared with those caused by susceptible bacteria [13]. A multicenter retrospective study performed in Korea suggested that SBP caused by ESBL-producing organisms was an independent prognostic factor for high in-hospital mortality in patients with LC and SBP $[49,79]$.

In SBP, the cause of the increasing prevalence of MDR bacteria has been suggested to be the increased use of long-term antibiotic prophylaxis or invasive procedures (e.g., catheterization, ablation of hepatocellular carcinoma) [45], although a significant decrease in the incidence of secondary SBP via the administration of norfloxacin has been reported [80].

\section{Conclusions}

On the basis of a review of previous studies on SBP and bacteremia in patients with LC, it is evident that these types of bacterial infections are life-threatening complications. The severity of liver dysfunction (underlying LC) and the presence of renal impairment such as type 1 HRS have been observed to have a particularly important influence on the prognosis of bacterial infections in patients with LC. Moreover, infections associated with MDR bacteria appear to worsen patient prognosis. Further research is required to better understand the various aspects of bacterial infections, including treatment, in the setting of LC.

\section{References}

1. Navasa M, Rimola A, Rodés J (1997) Bacterial infections in liver disease. Semin Liver Dis 17: 323-333.

2. Johnson DH, Cunha BA (2001) Infections in cirrhosis. Infect Dis Clin North Am 15: 363-371, vii.

3. Navasa M, Rodés J (2004) Bacterial infections in cirrhosis. Liver Int 24: 277-280. 
4. Garcia-Tsao G (2004) Bacterial infections in cirrhosis. Can J Gastroenterol 18: 405-406.

5. Bunchorntavakul C1, Chavalitdhamrong D (2012) Bacterial infections other than spontaneous bacterial peritonitis in cirrhosis. World J Hepatol 4: 158-168.

6. Tandon P, Garcia-Tsao G (2008) Bacterial infections, sepsis, and multiorgan failure in cirrhosis. Semin Liver Dis 28: 26-42.

7. Wiest R, Krag A, Gerbes A (2012) Spontaneous bacterial peritonitis: recent guidelines and beyond. Gut 61: 297-310.

8. Strauss E (2013) The impact of bacterial infections on survival of patients with decompensated cirrhosis. Ann Hepatol 13: 7-19.

9. Fernández J, Gustot T (2012) Management of bacterial infections in cirrhosis. J Hepatol 56 Suppl 1: S1-12.

10. Preda CM, Ghita R, Ghita C, Mindru C, Vlaicu L, et al. (2011) A retrospective study of bacterial infections in cirrhosis. Maedica (Buchar) 6: 185-192.

11. Cheruvattath R, Balan V (2007) Infections in Patients With End-stage Liver Disease. J Clin Gastroenterol 41: 403-411.

12. Soriano G, Guarner C, Tomás A, Villanueva C, Torras X, et al. (1992) Norfloxacin prevents bacterial infection in cirrhotics with gastrointestinal hemorrhage. Gastroenterology 103: 1267-1272.

13. Jalan R, Fernandez J, Wiest R, Schnabl B, Moreau R, et al. (2014) Bacterial infections in cirrhosis: a position statement based on the EASL Special Conference 2013. J Hepatol 60: 1310-1324.

14. Desai AP, Reau N, Reddy KG, Te HS, Mohanty S, et al. (2012) Persistent spontaneous bacterial peritonitis: a common complication in patients with spontaneous bacterial peritonitis and a high score in the model for end-stage liver disease. Therap Adv Gastroenterol 5: 275-283.

15. Papp M, Farkas A, Udvardy M, Tornai I (2007) [Bacterial infections in liver cirrhosis]. Orv Hetil 148: 387-395.

16. Bonnel AR, Bunchorntavakul C, Reddy KR (2011) Immune dysfunction and infections in patients with cirrhosis. Clin Gastroenterol Hepatol 9: 727-738.

17. Kang CI, Song JH, Chung DR, Peck KR, Yeom JS, et al. (2011) Liver cirrhosis as a risk factor for mortality in a national cohort of patients with bacteremia. J Infect 63: 336-343.

18. Navasa M, Follo A, Filella X, Jiménez W, Francitorra A, et al. (1998) Tumor necrosis factor and interleukin-6 in spontaneous bacterial peritonitis in cirrhosis: relationship with the development of renal impairment and mortality. Hepatology 27: 1227-1232.

19. Altman C, Grangé JD, Amiot X, Pelletier G, Lacaine F, et al. (1995) Survival after a first episode of spontaneous bacterial peritonitis. Prognosis of potential candidates for orthotopic liver transplantation. J Gastroenterol Hepatol 10: 47-50.

20. Shizuma T, Obata H, Hashimoto E, Hayashi N (2002) Clinical analysis of bacterial infections in cirrhotic patients with ascites. Acta Hepatologica Japonica 43: 446-452.

21. Terg R, Gadano A, Cartier M, Casciato P, Lucero R, et al. (2009) Serum creatinine and bilirubin predict renal failure and mortality in patients with spontaneous bacterial peritonitis: a retrospective study. Liver Int 29: 415-419.

22. Arroyo V, Fernández J (2011) Management of hepatorenal syndrome in patients with cirrhosis. Nat Rev Nephrol 7: 517-526.

23. Ginès A, Escorsell A, Ginès P, Saló J, Jiménez W, et al. (1993) Incidence, predictive factors, and prognosis of the hepatorenal syndrome in cirrhosis with ascites. Gastroenterology 105: 229-236.

24. Sort P, Navasa M, Arroyo V, Aldeguer X, Planas R, et al. (1999) Effect of intravenous albumin on renal impairment and mortality in patients with cirrhosis and spontaneous bacterial peritonitis. N Engl J Med 341: 403-409.

25. Garcia-Taso G (2001) Current management of the complications of cirrhosis and portal hypertension: variceal hemorrhage, ascites, and spontaneous bacterial peritonitis. Gastroenterology 120: 726-748.
26. Hsu SJ, Huang HC (2013) Management of ascites in patients with liver cirrhosis: recent evidence and controversies. J Chin Med Assoc 76: 123-130.

27. Fernández J, Acevedo J, Castro M, Garcia O, de Lope CR, et al. (2012) Prevalence and risk factors of infections by multiresistant bacteria in cirrhosis: a prospective study. Hepatology 55: 1551-1561.

28. Fagiuoli S, Colli A, Bruno R, Burra P, Craxì A, et al. (2014) Management of infections in cirrhotic patients: report of a Consensus Conference. Dig Liver Dis 46: 204-212.

29. Sheikhbahaei S, Abdollahi A, Hafezi-Nejad N, Zare E (2014) Patterns of antimicrobial resistance in the causative organisms of spontaneous bacterial peritonitis: a single centre, six-year experience of 1981 samples. Int J Hepatol 2014: 917856.

30. Wiest R, Lawson M, Geuking M (2014) Pathological bacterial translocation in liver cirrhosis. J Hepatol 60: 197-209.

31. Guarner C, Soriano G (2005) Bacterial translocation and its consequences in patients with cirrhosis. Eur J Gastroenterol Hepatol 17: 27-31.

32. Bellot P, Francés R, Such J (2008) [Bacterial translocation in cirrhosis]. Gastroenterol Hepatol 31: 508-514.

33. Bruns T, Zimmermann HW, Stallmach A (2014) Risk factors and outcome of bacterial infections in cirrhosis. World J Gastroenterol 20: 2542-2554.

34. Thalheimer U, Triantos CK, Samonakis DN, Patch D, Burroughs AK (2005) Infection, coagulation, and variceal bleeding in cirrhosis. Gut 54: 556-563.

35. Bert F, Johnson JR, Ouattara B, Leflon-Guibout V, Johnston B, et al. (2010) Genetic diversity and virulence profiles of Escherichia coli isolates causing spontaneous bacterial peritonitis and bacteremia in patients with cirrhosis. J Clin microbial 48: 2709-2714.

36. Corleto VD, Festa S, Di Giulio E, Annibale B (2014) Proton pump inhibitor therapy and potential long-term harm. Curr Opin Endocrinol Diabetes Obes 21: 3-8.

37. de Vos M, De Vroey B, Garcia BG, Roy C, Kidd F, et al. (2013) Role of proton pump inhibitors in the occurrence and the prognosis of spontaneous bacterial peritonitis in cirrhotic patients with ascites. Liver Int 33: 1316-1323.

38. Miura K, Tanaka A, Yamamoto T, Adachi M, Takikawa H (2014) Proton pump inhibitor use is associated with spontaneous bacterial peritonitis in patients with liver cirrhosis. Intern Med 53: 1037-1042.

39. Kwon JH, Koh SJ, Kim W, Jung YJ, Kim JW, et al. (2014) Mortality associated with proton pump inhibitors in cirrhotic patients with spontaneous bacterial peritonitis. J Gastroenterol Hepatol 29: 775-781.

40. European Association for the Study of the Liver (2010) EASL clinical practice guidelines on the management of ascites, spontaneous bacterial peritonitis, and hepatorenal syndrome in cirrhosis. J Hepatol 53: 397-417.

41. Evans LT, Kim WR, Poterucha JJ, Kamath PS (2003) Spontaneous bacterial peritonitis in asymptomatic outpatients with cirrhotic ascites. Hepatology 37: 897-901.

42. Mohan P, Venkataraman J (2011) Prevalence and risk factors for unsuspected spontaneous ascitic fluid infection in cirrhotics undergoing therapeutic paracentesis in an outpatient clinic. Indian J Gastroenterol 30: 221-224.

43. Oladimeji AA, Temi AP, Adekunle AE, Taiwo RH, Ayokunle DS (2013) Prevalence of spontaneous bacterial peritonitis in liver cirrhosis with ascites. Pan Afr Med J 15: 128.

44. Kamani L, Mumtaz K, Ahmed US, Ali AW, Jafri W (2008) Outcomes in culture positive and culture negative ascitic fluid infection in patients with viral cirrhosis: cohort study. BMC Gastroenterol 8: 59.

45. Salerno F, Cazzaniga M (2010) Therapeutic strategies and emergence of multiresistant bacterial strains. Intern Emerg Med 5 Suppl 1: S45-51.

46. Runyon BA (1990) Monomicrobial nonneutrocytic bacterascites: a variant of spontaneous bacterial peritonitis. Hepatology 12: 710-715. 
47. Pelletier G, Lesur G, Ink O, Hagege H, Attali P, et al. (1991) Asymptomatic bacterascites: is it spontaneous bacterial peritonitis? Hepatology 14: 112-115.

48. Wiest R, Garcia-Tsao G (2005) Bacterial translocation (BT) in cirrhosis. Hepatology 41: 422-433.

49. Tsung PC, Ryu SH, Cha IH, Cho HW, Kim JN, et al. (2013) Predictive factors that influence the survival rates in liver cirrhosis patients with spontaneous bacterial peritonitis. Clin Mol Hepatol 19: 131-139.

50. Shalimar, Acharya SK (2013) Difficult to treat spontaneous bacterial peritonitis. Trop Gastroenterol 34: 7-13.

51. Llovet JM, Planas R, Morillas R, Quer JC, Cabré E, et al. (1993) Shortterm prognosis of cirrhotics with spontaneous bacterial peritonitis: multivariate study. Am J Gastroenterol 88: 388-392.

52. Cheong HS, Kang CI, Lee JA, Moon SY, Joung MK, et al. (2009) Clinical significance and outcome of nosocomial acquisition of spontaneous bacterial peritonitis in patients with liver cirrhosis. Clin Infect Dis 48: 1230-1236.

53. Koulaouzidis A, Bhat S, Saeed AA (2009) Spontaneous bacterial peritonitis. World J Gastroenterol 15: 1042-1049.

54. Angeli P, Sanyal A, Moller S, Alessandria C, Gadano A, et al. (2013) Current limits and future challenges in the management of renal dysfunction in patients with cirrhosis: report from the International Club of Ascites. Liver Int 33: 16-23.

55. Salerno F, Gerbes A, Ginès P, Wong F, Arroyo V (2007) Diagnosis, prevention and treatment of hepatorenal syndrome in cirrhosis. Gut 56: 1310-1318.

56. Lata J (2012) Hepatorenal syndrome. World J Gastroenterol 18: 4978-4984.

57. Barbano B, Sardo L, Gigante A, Gasperini ML, Liberatori M, et al. (2014) Pathophysiology, diagnosis and clinical management of hepatorenal syndrome: from classic to new drugs. Curr Vasc Pharmacol 12: 125-135.

58. Mindikoglu AL, Weir MR (2013) Current concepts in the diagnosis and classification of renal dysfunction in cirrhosis. Am J Nephrol 38: 345-354

59. Salerno F, Monti V (2014) Hepatorenal syndrome type 1 and bacterial infection: a catastrophic association in patients with cirrhosis. Hepatology 59: 1239-1241.

60. Barreto R, Fagundes C, Guevara M, Solà E, Pereira G, et al. (2014) Type-1 hepatorenal syndrome associated with infections in cirrhosis: natural history, outcome of kidney function, and survival. Hepatology 59: 1505-1513.

61. Jeffries MA, Stern MA, Gunaratnam NT, Fontana RJ (1999) Unsuspected infection is infrequent in asymptomatic outpatients with refractory ascites undergoing therapeutic paracentesis. Am J Gastroenterol 94: 2972-2976.

62. Toledo C, Salmerón JM, Rimola A, Navasa M, Arroyo V, et al. (1993) Spontaneous bacterial peritonitis in cirrhosis: predictive factors of infection resolution and survival in patients treated with cefotaxime. Hepatology 17: 251-257

63. Lippi G, Danese E, Cervellin G, Montagnana M (2014) Laboratory diagnostics of spontaneous bacterial peritonitis. Clin Chim Acta 430: 164-170.
64. Kuo CH, Changchien CS, Yang CY, Sheen IS, Liaw YF (1991) Bacteremia in patients with cirrhosis of the liver. Liver 11: 334-339.

65. Thulstrup AM, Sørensen HT, Schønheyder HC, Møller JK, Tage-Jensen U (2000) Population-based study of the risk and short-term prognosis for bacteremia in patients with liver cirrhosis. Clin Infect Dis 31: 1357-1361.

66. Barnes PF, Arevalo C, Chan LS, Wong SF, Reynolds TB (1988) A prospective evaluation of bacteremic patients with chronic liver disease. Hepatology 8: 1099-1103.

67. Graudal N, Milman N, Kirkegaard E, Korner B, Thomsen AC (1986) Bacteremia in cirrhosis of the liver. Liver 6: 297-301.

68. Shizuma T, Fukuyama N (2012) Investigation into bacteremia and spontaneous bacterial peritonitis in patients with liver cirrhosis in Japan. Turk J Gastroenterol 23: 122-126.

69. Caly WR, Strauss E (1993) A prospective study of bacterial infections in patients with cirrhosis. J Hepatol 18: 353-358.

70. Munita S JM, Araos B R, Pérez G J, Alvarez V A, Canals C M, et al. (2011) [Bacteremia in patients with liver cirrhosis]. Rev Chilena Infectol 28: 35-39.

71. Yoshida H, Hamada T, Inuzuka S, Ueno T, Sata M, et al. (1993) Bacterial infection in cirrhosis, with and without hepatocellular carcinoma. Am J Gastroenterol 88: 2067-2071.

72. Rosa H, Silvério AO, Perini RF, Arruda CB (2000) Bacterial infection in cirrhotic patients and its relationship with alcohol. Am J Gastroenterol 95: 1290-1293.

73. Runyon BA (1993) Bacterial infections in patients with cirrhosis. J Hepatol 18: 271-272.

74. Puri AS, Puri J, Ghoshal UC, Sharma BC, Saraswat VA, et al. (1996) Frequency, microbial spectrum and outcome of spontaneous bacterial peritonitis in north India. Indian J Gastroenterol 15: 86-89.

75. Arvaniti V, D’ Amico G, Fede G, Manousou P, Tsochatzis E, et al. (2010) Infections in a patients with cirrhosis increase mortality four-fold and should be used in determining prognosis. Gastroenterology 139: 1246-1256.

76. Terra C, Guevara M, Torre A, Gilabert R, Fernández J, et al. (2005) Renal failure in patients with cirrhosis and sepsis unrelated to spontaneous bacterial peritonitis: value of MELD score. Gastroenterology 129: 1944-1953.

77. Bouslama K, Houissa F, Dabbeche R, Bouzaidi S, Trabelsi S, et al. (2013) Prevalence and risk factor of renal dysfunction induced by bacterial infection other than spontaneous bacterial peritonitis in patients with cirrhosis. Tunis Med 91: 391-395.

78. Grauda N, Hubeck B, Bonde J, Thomsen AC (1987) The prognostic significance of bacteremia in hepatic cirrhosis. Liver 7: 138-141.

79. Heo J, Seo YS, Yim HJ, Hahn T, Park SH, et al. (2009) Clinical features and prognosis of spontaneous bacterial peritonitis in korean patients with liver cirrhosis: a multicenter retrospective study. Gut Liver 3: 197-204.

80. Ginés P, Rimola A, Planas R (1990) Norfloxacin prevents spontaneous bacterial peritonitis recurrence in cirrhosis: results of double-blind, placebo-controlled trial. Hepatology 12: 716-724. 